\title{
Giant Bursitis of Wrist and Multiple Tenosynovitis of Hand with Rice Body Formation: Unusual Case of an Atypical Mycobacteria Infection
}

\author{
Kone Samba1 ${ }^{*}$, Krah K. Leopold ${ }^{2}$, Traore Moctar ${ }^{3}$, Gbane Mariam4, Koffi Gerard ${ }^{1}$, \\ Kouassi Adelaide ${ }^{2}$, Ngandeu Astrid ${ }^{4}$ \\ ${ }^{1}$ Traumatology and Orthopedics Surgery of the University Hospital of Cocody, Abidjan, Côte d'Ivoire \\ ${ }^{2}$ Traumatology and Orthopedics Surgery of the University Hospital of Bouaké, Bouaké, Côte d'Ivoire \\ ${ }^{3}$ Traumatology and Orthopedics Surgery of the University Hospital of Treichville, Abidjan, Côte d'Ivoire \\ ${ }^{4}$ Rheumatology Service of the University Hospital of Cocody, Abidjan, Côte d'Ivoire \\ Email: *k.samba06@gmail.com
}

Received 25 March 2016; accepted 6 July 2016; published 9 July 2016

Copyright (C) 2016 by authors and Scientific Research Publishing Inc.

This work is licensed under the Creative Commons Attribution International License (CC BY).

http://creativecommons.org/licenses/by/4.0/

(c) (i) Open Access

\begin{abstract}
We report an unusual manifestation of nontuberculous mycobacterial infection characterized by a giant bursitis on wrist and multiple tenosynovitis with many rice bodies formations. The clinical and radiological examinations are neither rather sensitive nor rather specific. The nuclear imagery of rice bodies formations provides elements of guidance. Cause of absence of the germ isolation, diagnosis was retained on probability items based on a suspicion of arguments beam: clinical, biological, bacteriological and histological. The patient was treated with medical and surgical procedure and provided a satisfactory evolution. At follow-up of $\mathbf{1 5}$ months, there were no clinical signs of local recurrence. Through a literature review, the problem of diagnosis of certainty will be discussed.
\end{abstract}

\section{Keywords}

Rice Body Formations, Nontuberculous Mycobacteria, Tenosynovitis, Bursitis, Hand

\section{Introduction}

Inflammation of the synovium (bursa, tendon sheath) with rice body is a particular clinical entity and little at${ }^{*}$ Corresponding author.

How to cite this paper: Samba, K., Leopold, K.K., Mocta, T., Mariam, G., Gerard, K., Adelaide, K. and Astrid, N. (2016) Giant Bursitis of Wrist and Multiple Tenosynovitis of Hand with Rice Body Formation: Unusual Case of an Atypical Mycobacteria Infection. Open Journal of Rheumatology and Autoimmune Diseases, 6, 45-50. http://dx.doi.org/10.4236/ojra.2016.63008 
tends. Particles named "rice body", due to their resemblance to shiny rice grains, were first described by Reise in 1895 [1]. Rice bodies formations are classically reported during non-infectious chronic inflammatory process [2] [3] (rheumatoid arthritis, inflammatory arthropathy) or at the time caused by Mycobacterium tuberculosis [4] [5]. However, nontuberculous mycobacteria are often involved [6] [7].

Nontuberculous mycobacteria (NTM) or atypical mycobacteria are acid-fast bacillus (AFB) including that more than fifty species have been identified. Typically they were found in the environment hydrotellurique (wet soil, waterways, marsh, estuary) [8]. Only dozen of them are potentially pathogenic for humans. This pathogenicity is reported more frequently in lung, skin and nodes [9].

In some circumstances and during at the time of supporting (environment, occupation, land), it may affect synovial bursa and tendon sheaths with non-specific clinical or unusual expressions.

Unlike pyogenic bacteria infections, mycobacterial infections have slower evolution (weeks or months), with less severe symptoms. Because of indolence, diagnosis is often delayed, leading to increase morbidity.

Biology and nuclear imaging provides guidance.

Certainty diagnostic is based on identification and isolation germ (by bacteriological and/or histological proof on samples) which is paradoxically often difficult to obtain.

Treatment proposed is a combination of an adapted specific antibiotic and wide surgical excision (which decreases bacterial load).

We report an unusual case of concomitant infection to non-tuberculosis mycobacteria characterized by a giant bursitis of the wrist, multiple tenosynovitis of flexor of hand with rice bodies' formations.

\section{Case Report}

A 36-year old lady working as fishmonger-saleswoman consulted for a swelling of the left wrist with paraesthesiae in the fingers, lasting for 9 months.

In the beginning it was just a simple swelling in the front of the wrist; thereafter gradually appeared a paraesthesiae on her five fingers, with an increase in the volume of swelling and vasomotor disorder without fever.

This clinical picture has led to difficulties for daily activities and even functional impairment on hand. Examination of the hand and wrist reveals swelling at anterior face of the wrist, of hypothenar and thénarienne eminences with a deficit of bending of the fifth finger (Figure 1).

The swelling in the wrist was renitent, firm, and sensitive, with no signs of inflammation. There were no satellite lymph's nodes. Wrist movements (palmar flexion, dorsiflexion, radio-ulnar deviation) were possible but painful at the maximal amplitude. Phalen's maneuver triggers pains.

The rest of the musculoskeletal and general examination was unremarkable. There was no fever or general body state alteration. Apart from a human immunodeficiency virus (HIV) infection detected three years ago and followed since them, she didn't have any past medical history (no traumatism, no inflammatory or systemic disease). Standard X-ray of wrist and hand were normal except a shade of the soft tissues opposite to the wrist and the metacarpals base.

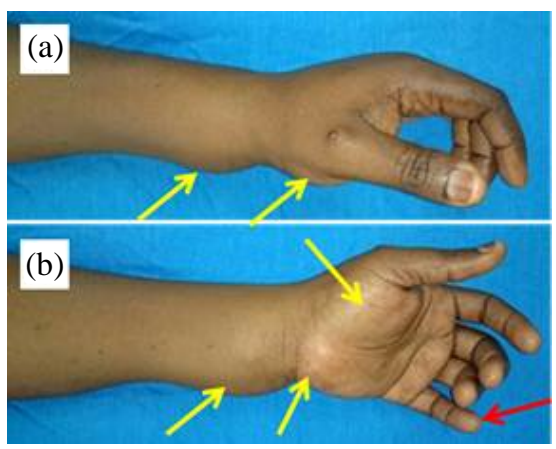

Figure 1. Local appearance of wrist and hand ((a) medio-lateral, (b) anterior) side view: large swelling (arrow in yellow: wrist, hypothenar and thenar eminence), spontaneous rupture of the 5th finger flexor (arrow in red). 
Biology revealed leukopenia without inflammatory syndrome (Erythrocytes sedimentation rate was of $4 \mathrm{~mm} /$ $\mathrm{h} 1$, and $\mathrm{C}$ reactive protein was negative). The wrist ultrasound evoked synovial cyst with calcified formations.

Magnetic resonance imaging (MRI) revealed a giant bursitis of the wrist with many formations having the appearance of rice body (Figure 2), and multiple tenosynovitis of the hand's flexor tendons (Figure 3).

Seeing rice bodies was an intraoperative surprise for us (Figure 4) as well as spontaneous rupture of the 5th finger flexor tendon surface (Figure 1). Complete resection (bursectomy, synovectomy) of all formations was carried out (Figure 5). A wrist and hand immobilization equipment was put for 15 days. The rehabilitation had been prescribed in post operative care. A probabilistic antibiotic by ofloxacin was founded (400 $\mathrm{mg}$ by day).

The excised elements were analyzed by bacteriological and histological. Direct bacteriology examination (Ziehl-Neelsen) confirms presence of acid-fast bacilli (Figure 5), but culture was unsuccessful. Histology showed nonspecific inflammatory granuloma (giant cells without caseous necrosis).

A general assessment in search of a potential tuberculosis hearth (chest X-ray, spittle, urines) was normal. Tuberculin intradermal test was no reactive. Rheumatoid factor and antinuclear antibodies were negative too.

Year term of investigations NTM etiology was strongly suspected. Then we decided to continue initial therapy antibiotic inpartnership with rifampicin (600 mg by day) and isoniazid (300 mg by day) during 12 months. Immediate outcome was favorable with considerable regression of paraesthesiae and normalization of clinical picture after 8 weeks of treatment.
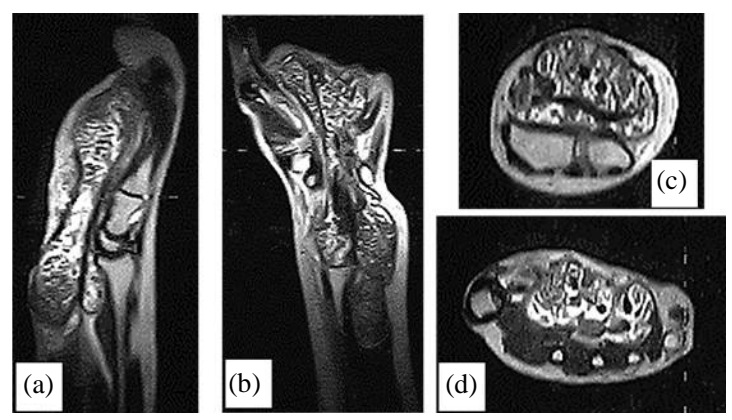

Figure 2. MRI of the wrist and hand [(a): Sagittal, (b): Coronal, (c): Axial wrist, (d): Axial hand) shows at DPT2 giant bursitis with rice bodies' formation (hyper "liquid" signal punctuated multiple hypointense body).

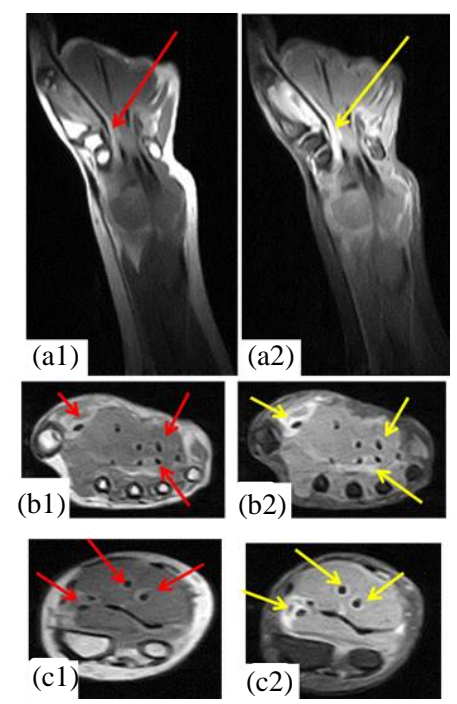

Figure 3. MRI of the wrist and hand [(a): Sagittal, (b): Axial hand, (c): Axial wrist)] (1: MRIT1/2: MRI WTF1 with gadolinium). An extension synovitis of all digital flexor sheaths. Fluid around the tendon is low signal intensity (arrow in red) which enhances high signal intensity (arrow in yellow) around all flexor tendon sheaths. 

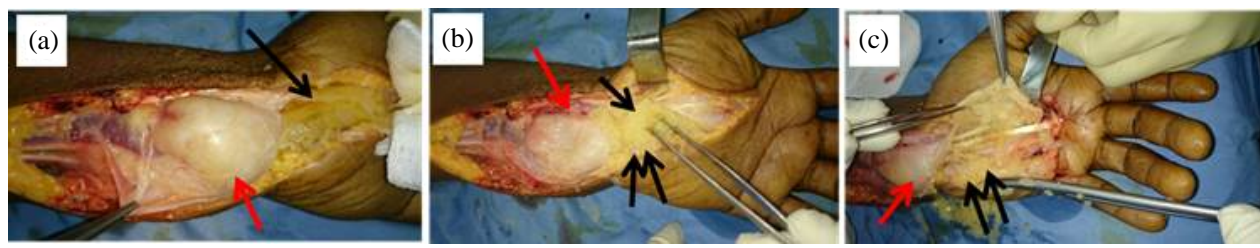

Figure 4. Intraoperative local appearance of wrist and hand (medio-lateral, anterior) side view: a giant bursitis (arrow in red) of the wrist (a), multiple tenosynovitis of flexor tendons with many formations having the appearance of rice body (arrow in black) (b) (c).

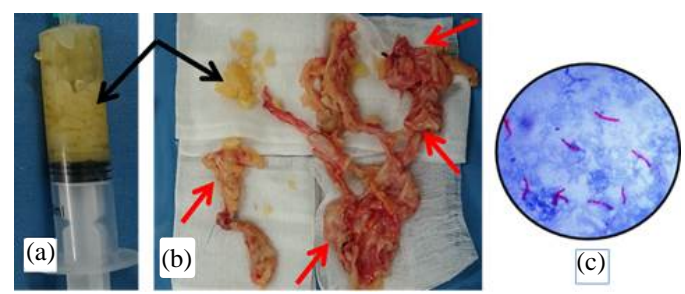

Figure 5. Local appearance of complete resection: (a) rice bodies formation (arrow in black); (b) bursectomy, synovectomy (arrow in red); (c) Ziehl-Neelsen coloration, acid-fast bacilli.

The patient started again her professional activities without any difficulties.

At 18 months follow-up there were no signs of local relapse.

\section{Discussion}

Hand Infections due to NTM are not numerous. Because of their rarity they are not well known in our daily practices.

In literature [10]-[12] NTM tenosynovitis have been reported, but ours is unique because of its scope to five flexor tendons and the simultaneous combination of giant bursitis of wrist. Moreover bursitis wrist is still less exceptional topography and its association with rice bodies is another interest of this work.

To date no transmission by contagion from human or animal origin which has been identified, they are attributed to factors of environmental and occupational exposures (fishmonger fisherman, cook, immunosuppression, bird breeders).

In favor of pre-existing factors [12] such as lung injury, accidental injury (trauma, wound, nosocomial infection) or immunosuppression condition (HIV, renal graft, immunosuppressive treatment) these bacteria are opportunistic. For some author's that immunosuppression is a risk factor of NTM infections. This may be related to a kidney transplant or after immunosuppressive treatment or caused by HIV infection.

In our patient's immunocompromised (HIV) condition, associated with environmental and occupational exposures (fisherwoman) factors could explain occurrence of this infection. The clinical picture of the patient is in agreement with the few cases elucidated in the literature [10]-[12]: nonspecific signs; a slow and chronic evolution; inflammatory signs discrete or absent. This insidious evolution becomes corollary of a chronicity which can be responsible for advanced lesions [13]. Osteitis [9], or bone erosion [12] is brought back in literature, in our case it was a spontaneous rupture of the flexor tendon of the 5th ray.

Rice bodies are small bodies fibrin whose mechanism is not completely understood but their presence indicates chronically synovial inflammatory [14]. Rice body formation may occur in intra-articular structures, at tendon insertions and synovial structures like periarticular bursa of the shoulder, knee, wrist and ankles, which are the most common sites of involvement. According to author [5], rice bodies are formed by the necrotized particles which break away from the synovium and adhere to the fibrin in the joint space, tendon sheath or inside the bursa. Diagnosis with classical radiography is challenging. Arthrography, ultrasonography and magnetic resonance imaging (MRI) are useful techniques in preoperative diagnosis.

The sight of these formations intraoperative was surprising that despite the reported nuclear imaging guidance. Indeed the appearance of on MRI T2-weighted (hyper "liquid" signal punctuated multiple hypointense body) [15] is very evocative of training in rice body (Figure 4). However this aspect is not specific to Mycobacterium tuberculosis infection because they were also observed in NTM infection [15] [16]. 
Mycobacterium (M) marinum and M. kansasii are the most frequent causes of NTM tenosynovitis [9].

Less frequently, M. aviumcomplex, M. szulgai, M. terrae, M. fortuitum, M. chelonae, M. abscessus, M. malmoense, and M. xenopi are found [9].

In our working conditions certainty diagnosis is often difficult to obtain by the usual technique (culture) of isolation because frequently less contributory such as our case.

Molecular biology techniques (Polymerase Chain Reaction) can also be used to detect and identify the main species of mycobacteria [17]. Unfortunately the cost for its realization seems high for our population; this shows difficulty of certainty diagnosis and highlights differential diagnosis.

Indeed the finding of inflammatory giant cell granuloma without caseous necrosis is highly suggestive of NTM infection as well as sarcoidosis. As against normal investigation for our patient (lymphnode, pulmonary assessment, biological) we have eliminated it (sarcoidosis).

Owing to endemic character of mycobacterium in our country, etiology of mycobacterium was suspected in our patient before this chronic course, insidious evolution; facing the HIV field of immunosuppression; in front of a rice body training and AFB identification in direct examination.

All these factors have constrained us to be used a probability of diagnosis based on suspicion arguments cited above. The strong probability that this infection is caused by NTM arises histological result in associated with environmental and professionals exposure factors that our patient had.

Surgery is often necessary [9]-[11]. Bursectomy, synovectomy or debridement are essential. For us it is the only alternative to undertake bacteriological and histological investigations. Moreover, it participates in the control of infection (by decreasing bacterial load) in combination with specific antibiotics especially in multiple forms and extended as such case of our patient.

Medical treatment plan is based on specific antibiotic even if the protocols are not clearly codified, either in their drug associations or in their duration [18]. According to the recommendations of experts or learned society it is based on the combination of macrolide (or cycline), quinolone and anti-tuberculous treatment (rifampicin, isoniazid, ethambutol) between 3 and 9 months [9]-[11]. It should have to begin quickly soon after surgical treatment from empirical choices, and later be adapted if necessary (to stand up to treatment, intolerant or allergic).

On account of his immunocompromised (HIV) condition and extensive form, our patient was treated during 12 month. Certainly there were no signs of local relapse at 18 months follow up, but we can occult with certitude possible apparition of local recurrence or elsewhere (lung, skin).

\section{Conclusions}

Nontuberculous mycobacterial tenosynovitis has been reported in the literature, and the absence of clinical specific signs often delays the diagnosis. The diagnosis of certainty is based on identification and isolation of the Mycobacterium. In spite of recent progress of the techniques of identification and isolation, certainty diagnosis remains difficult to obtain. Sometimes, it forced us to settle a diagnosis of probability based on a beam of arguments of suspicion: clinical, biological, bacteriological and histological. It is all the interest of an often instructive interrogation which finds the environmental or professional factors of exposure.

Anti-tuberculous treatment is certainly effective, but surgery keeps its place (diagnostic and therapeutic interest). In short, the difficulty in NTM hand infections is more to establish the diagnosis of certainty than effective treatment.

\section{Conflict of Interests}

The authors declare no conflict of interest.

The patient was informed and gave contentment for this article.

\section{Author's Contributions}

All the authors contributed to the writing of this manuscript, and had read and approved the final version.

\section{References}

[1] Reise, H. (1895) Die Reiskorpschen in tuberculserkrankensynovalsacken. Deutsche Zeitschrift für Chirurgie, 42, 1. 
[2] Ergun, T., Lakadamyali, H. and Aydin, O. (2014) Flexor Tendon Tenosynovitis with Rice Body Formation in Rheumatoid Arthritis. JBR-BTR, 97,123.

[3] Cuomo, A., Pirpiris, M. and Otsuka, N.Y. (2006) Case Report: Biceps Tenosynovial Rice Bodies. Journal of Pediatric Orthopaedics B, 15, 423-425. http://dx.doi.org/10.1097/01.bpb.0000228392.62678.df

[4] Hung, M.H., Ho, K.C. and Huang, K.F. (2011) Tuberculous Tenosynovitis with Rice Body Formation. ANZ Journal of Surgery, 81, 572. http://dx.doi.org/10.1111/j.1445-2197.2011.05811.x

[5] Raju, K.P., Mohan Kumar, J. and Shetty, R. (2013) Tuberculous Tenosynovitis of Ankle with Rice Bodies. The Foot and Ankle Online Journal, 6, 1.

[6] Tyllianakis, M., Kasimatis, G. and Athanaselis, S. (2006) Rice-Body Formation and Tenosynovitis of the Wrist: A Case Report. Journal of Orthopaedic Surgery, 14, 208-211.

[7] Ergun, T., Lakadamyali, H. and Aydin, O. (2008) Multiple Rice Body Formation Accompanying the Chronic Nonspecific Tenosynovitis of Flexor Tendons of the Wrist. Radiation Medicine, 26, 545-548. http://dx.doi.org/10.1007/s11604-008-0270-7

[8] Falkinham, J.O. (1996) Epidemiology of Infection by Nontuberculous Mycobacteria. Clinical Microbiology Reviews, 9, 177-215.

[9] (2008) Synthèse: Mycobactérioses atypiques: maladies infectieuses émergentes? Revue des Maladies Respiratoires, 25, 57-59.

[10] Cheung, J.P.-Y., et al. (2010) Mycobacterium marinum Infection of the Hand and Wrist. Journal of Orthopaedic Surgery, 18, 98.

[11] Kang, G.C.W., Gan, A.W.T., Yam, A., et al. (2010) Mycobacterium abscessus Hand Infections in Immunocompetent Fish Handlers: Case Report. The Journal of Hand Surgery, 35, 1142-1145.

[12] Hyun, J.Y., Jong, W.K., Young, C.Y., and Sang-Hee, C. (2011) Nontuberculous Mycobacterial Tenosynovitis in the Hand: Two Case Reports with the MR Imaging Findings. Korean Journal of Radiology, 12, 745-749. http://dx.doi.org/10.3348/kjr.2011.12.6.745

[13] Pattamapaspong, N., Muttarak, M. and Sivasomboon, C. (2011) Tuberculosis Arthritis and Tenosynovitis. Seminars in Musculoskeletal Radiology, 15, 459-469. http://dx.doi.org/10.1055/s-0031-1293492

[14] Cheung, H.S., Ryan, L.M., Kozin, F. and McCarty, D.J. (1980) Synovial Origins of Rice Bodies in Joint Fluid. Arthritis \& Rheumatology, 23, 72-76. http://dx.doi.org/10.1002/art.1780230112

[15] Chen, A., Wong, L.Y., Sheu, C.Y. and Chen, B.F. (2002) Distinction multiples formation de corps de riz dans bursite chronique sous-acromiodeltoïdienne de chondromatose synoviale. Skeletal Radiology, 31, 119-121. http://dx.doi.org/10.1007/s002560100412

[16] Lee, E.Y., Rubin, D.A. and Brown, D.M. (2004) Recurrent Mycobacterium marinum Tenosynovitis of the Wrist Mimicking Synovial Chondromatosis Is Extraarticular MR Images. Skeletal Radiology, 33, 405-408.

[17] Mrabet, D., et al. (2011) Tuberculosis Tenosynovitis of the Extensor Tendons of the Wrist. BMJ Case Reports, pii: bcr0620114347.

[18] Griffith, D.E., Aksamit, T., Brown-Elliott, B.A., Catanzaro, A., et al. (2007) An Official ATS/IDSA Statement: Diagnosis, Treatment, and Prevention of Nontuberculous Mycobacterial Diseases. American Journal of Respiratory and Critical Care Medicine, 175, 367-416. http://dx.doi.org/10.1164/rccm.200604-571ST 


\section{Submit or recommend next manuscript to SCIRP and we will provide best service for you:}

Accepting pre-submission inquiries through Email, Facebook, LinkedIn, Twitter, etc.

A wide selection of journals (inclusive of 9 subjects, more than 200 journals)

Providing 24-hour high-quality service

User-friendly online submission system

Fair and swift peer-review system

Efficient typesetting and proofreading procedure

Display of the result of downloads and visits, as well as the number of cited articles

Maximum dissemination of your research work

Submit your manuscript at: http://papersubmission.scirp.org/ 